\title{
Assembly of DNA-Functionalized Gold Nanoparticles with Gaps and Overhangs in Linker DNA
}

\author{
Brendan D. Smith, Neeshma Dave, Po-Jung Jimmy Huang, and Juewen Liu* \\ Department of Chemistry, Waterloo Institute for Nanotechnology, University of Waterloo, 200 \\ University Avenue West, Waterloo, Ontario, N2L 3G1, Canada
}

Email: liujw@uwaterloo.ca

Fax: 519 746-0435

Received: November 19, 2010

Revised: March 18, 2011

Published: April 04, 2011

This document is the Accepted Manuscript version of a Published Work that appeared in final form in The Journal of Physical Chemistry C, copyright @ American Chemical Society after peer review and technical editing by publisher. To access the final edited and published work see http://dx.doi.org/10.1021/jp111073w 


\begin{abstract}
DNA-directed assembly of gold nanoparticles (AuNPs) has been extensively studied because of its important applications in analytical chemistry, materials science, and nanomedicine. In a typical system, two DNA-functionalized AuNPs are assembled via a linker DNA to form large aggregates. In majority of the previous reports, the linker DNA is fully base paired with no gaps or overhangs present. Introducing such non-base-paired regions in the linker DNA has been recently shown to be important for making stimuli-responsive materials and in crystallization of such AuNPs. In this work, we systematically studied the effect of introducing gaps and overhangs in the linker DNA to understand the kinetics of assembly and the melting transition of these aggregates. We found that the assembly kinetics decreased with increasing linker DNA length. The melting temperature decreased with the loss of base stacking by introducing gaps as well as the steric effect of overhangs. Additional insights were obtained by measuring the melting curves of the free DNAs in the absence of AuNPs. For example, it appeared that DNA base stacking at the nick site was favored in assembled nanoparticles compared to that in free DNA. Our results indicate that while it is possible to form AuNP assemblies with linker DNAs containing various types of unpaired regions, these kinetic and thermodynamic factors need to be considered when designing related sensors and materials.
\end{abstract}

\title{
Introduction
}

DNA-directed assembly of inorganic nanoparticles has become a well-established method for obtaining nanomaterials with well-defined structures and functions. ${ }^{1-8}$ These materials are attractive because the assembly process is programmable in terms of DNA length, sequence, structure, and nanoparticle composition. The number of nanoparticles in each assembly can be controlled to form 
oligomers or large aggregates. ${ }^{9,10}$ It is even possible to reversibly control the distance between assembled nanoparticles as well as forming nanoparticle crystals. ${ }^{11-13}$ At the same time, since the linkages are realized by the reversible DNA base pairing interaction, assembled structures can be disassembled by either heat (e.g. through DNA melting) ${ }^{14-16}$ or chemical stimuli (e.g. through enzymatic DNA cleavage or DNA conformational change). ${ }^{17-19}$ For these reasons, DNA-directed assembly has found a wide range of applications in analytical chemistry, ${ }^{6,20,21}$ materials science, ${ }^{11-13}$ nanotechnology, ${ }^{22}$ and nanomedicine..$^{23,24}$

For example, gold nanoparticles (AuNPs) can be heavily functionalized with thiol-modified DNA and polymerized to form large aggregates in the presence of linker DNA. This results in the color of AuNPs changing from red to blue due to the coupling of gold surface plasmon when AuNPs are close to each other. ${ }^{25}$ This distinct color change makes it possible to construct colorimetric sensors for detection of nucleic acids, ${ }^{14}$ metal ions, ${ }^{26-30}$ small molecules, ${ }^{31-33}$ and even cells.${ }^{34}$ In addition to AuNPs, many other inorganic materials including magnetic nanoparticles, ${ }^{35,36}$ quantum dots, ${ }^{37}$ and silica nanoparticles ${ }^{38}$ have also been assembled by DNA to allow a reversible control on their respective optical or magnetic properties.

Since it is possible to precisely control the distance between nanoparticles, DNA-directed assembly offers us a useful system to study the physical properties of nanomaterials. ${ }^{25,39}$ Such properties are often studied using a configuration shown in Figure 1A, where two AuNPs are functionalized with different DNA sequences and they can be assembled by a linker DNA. ${ }^{25,40,41}$ Such a design is highly programmable because the size and shape of each AuNP and the DNA sequence can all be changed as long as certain DNA base pairing interactions are maintained. ${ }^{42}$ With this model system, many important parameters have been characterized, including the effect of particle size, salt concentration, melting 
transition, DNA density, defects in DNA sequences and the addition of a polynucleotide spacer to the thiol DNA. ${ }^{16,25,40,41,43}$

In most previous studies, all the nucleotides in the linker DNA were base-paired to the DNA attached to the AuNPs and no unpaired regions were present. For many applications, however, it is useful and necessary to introduce single-stranded regions in linker DNA. For example, to detect DNA or RNA in biological samples, the target nucleic acid is likely to be very long and functionalized AuNPs can only probe a short region within the target. As a result, overhang sequences are likely to be present. Some DNAs (e.g. aptamers) can selectively bind small molecules and aptamers are usually single-stranded. ${ }^{44-}$ ${ }^{46}$ A number of sensors have been prepared by combining aptamers with AuNPs. ${ }^{6,21,27,31}$ In addition to analytical applications, non-base pairing nucleotides also play crucial roles in materials science. For example, a single adenine base insertion was identified to be important for crystallization of DNAfunctionalized AuNPs. ${ }^{11,12,47,48}$ In a recent report, nucleotide insertions were introduced in the linker DNA to reversibly control the inter-nanoparticle distance. ${ }^{13}$ Given the importance of single-stranded regions in DNA-assembled nanostructures, little is known about their effect on the property of the resulting AuNP assembly in terms of thermodynamics and kinetics.11,14,39,49-51

Herein, we report a systematic study on AuNP assembly kinetics and melting transitions using linker DNAs containing varying lengths of base insertions (i.e. gaps) and overhangs. Kinetic studies are important in terms of preparing such AuNP aggregates while melting studies provide information about their thermodynamic stability as well as a tool for DNA detection. ${ }^{14,16}$ Our results indicate that the more nucleotides are present as gaps or overhangs, the slower the assembly process. At the same time, these non-base-paired regions decreased the melting temperature $\left(T_{m}\right)$ of the assembled AuNPs through the loss of base stacking and increased steric effects. 


\section{Materials and Methods}

DNA and Chemicals. All the DNA samples were obtained from Integrated DNA Technologies (IDT,

Coralville, IA). The DNA sequences and modifications are listed in Table 1 . $\mathrm{HAuCl}_{4}$ was purchased from VWR. Sodium citrate, 4-(2-hydroxyethyl)-1-piperazineethanesulfonic acid and its sodium salt (HEPES), and $\mathrm{NaCl}$ were purchased from Mandel Scientific Inc. (Guelph, Ontario, Canada). Tris(2carboxyethyl)phosphine (TCEP) was purchased from Sigma. Millipore water was used for all of the experiments. 
Table 1. DNA sequences and modifications used in this study.

\begin{tabular}{|c|c|}
\hline Name & Sequences and modifications (listed from $5^{\prime}$ to $\left.3^{\prime}\right)^{*}$ \\
\hline 3'SH-DNA1 & TCACAGATGCGT-SH \\
\hline 5'SH-DNA1 & SH-CCCAGGTTCTCT \\
\hline 3'SH-DNA2 & TCACAGATGCGT-AAAAAAAAA-SH \\
\hline 5'SH-DNA2 & SH-AAAAAAAAACCCAGGTTCTCT \\
\hline Linker & ACGCATCTGTGAAGAGAACCTGGG \\
\hline Linker-G1 & ACGCATCTGTGATAGAGAACCTGGG \\
\hline Linker-G3 & ACGCATCTGTGATCTAGAGAACCTGGG \\
\hline Linker-G5 & ACGCATCTGTGATCTCTAGAGAACCTGGG \\
\hline Linker-G7 & ACGCATCTGTGATCTCTCTAGAGAACCTGGG \\
\hline Linker-G10 & ACGCATCTGTGATCTCTCTCTCAGAGAACCTGGG \\
\hline Linker-G15 & ACGCATCTGTGAGGTTGGTGTGGTTGGAGAGAACCTGGG \\
\hline Linker-G21 & ACGCATCTGTGATTTGGTTGGTGTGGTTGGTTTAGAGAACCTGGG \\
\hline Linker-G27 & ACGCATCTGTGATTTGGGTTAGGGTTAGGGTTAGGGTTTAGAGAACCTGGG \\
\hline Linker-O10 & ACACAACGCATCTGTGAAGAGAACCTGGGACACA \\
\hline Linker-O20 & ACACAACACAACGCATCTGTGAAGAGAACCTGGGACACAACACA \\
\hline \multirow{2}{*}{ Linker-O36 } & ACAACACAACACAACACAACGCATCTGTGAAGAGAACCTGGGACACAACACAA \\
\hline & CACAACA \\
\hline
\end{tabular}

*The inserted sequences (Linker-G1 to G27) and the hybridization sequences for DNAs containing overhangs (Linker O10, O20, and O36) are highlighted by an underline. 
Preparation and functionalization of AuNPs. AuNPs (13 nm diameter) were prepared using a standard citrate reduction method described in the literature. ${ }^{52}$ The starting $\mathrm{HAuCl}_{4}$ concentration was $1 \mathrm{mM}$ and the extinction at $520 \mathrm{~nm}$ was $~ 2.3$ for the as-prepared AuNPs. Ligand exchange with thiolmodified DNAs on AuNPs was preformed according to a previously reported protocol. ${ }^{53}$ To remove free DNA, $500 \mu \mathrm{L}$ of each type of AuNPs was centrifuged at $15000 \mathrm{rpm}$ for $15 \mathrm{~min}$. The supernatant was then carefully removed using a micropipette. The particles were washed with $500 \mu \mathrm{L}$ of buffer A $(25 \mathrm{mM} \mathrm{HEPES}, \mathrm{pH}$ $7.6,100 \mathrm{mM} \mathrm{NaCl}$ ) each, and then spun once more. The supernatant was removed, and the $3^{\prime}$ and $5^{\prime}$ thiolDNA functionalized AuNPs were combined and dispersed in $500 \mu \mathrm{L}$ of buffer B $(25 \mathrm{mM}$ HEPES, pH 7.6, $300 \mathrm{mM} \mathrm{NaCl})$.

Kinetics studies. AuNP assembly kinetics were measured in a temperature controlled quartz microcuvette with a final volume of $100 \mu \mathrm{L}$ at $35^{\circ} \mathrm{C}$ in buffer B. The two kinds of functionalized AuNPs were mixed at 1:1 ratio and diluted to have an extinction of $\sim 1.2$ at $520 \mathrm{~nm}(\sim 5 \mathrm{nM}$ AuNPs $) .1 \mu \mathrm{L}$ linker DNA was added to give a final concentration of $200 \mathrm{nM}$ to initiate the assembly process. The extinction spectra were taken using a UV-Visible spectrometer (Agilent 8453) with 1 min interval for at least 10 $\min$.

Melting curves. To study the melting transition, assembled AuNPs were first prepared by mixing the above combined AuNPs (10 nM each) and $200 \mathrm{nM}$ linker DNA in buffer B at $50{ }^{\circ} \mathrm{C}$ for 5 min and then slowly cooled to $4{ }^{\circ} \mathrm{C}$ over one day. The formed AuNP aggregates were harvested by centrifugation. After removal of the supernatant solution, the aggregates were dispersed in buffer C (25 mM HEPES, $\mathrm{pH} 7.6,50 \mathrm{mM} \mathrm{NaCl})$. The samples were then placed in microcuvettes and sealed with parafilm to prevent evaporation. The temperature of the samples was controlled using a circulating water bath with a temperature change rate of $1{ }^{\circ} \mathrm{C} / \mathrm{min}$. The temperature was raised in increments of $2{ }^{\circ} \mathrm{C}$ until melting begun to occur, at which point the temperature was raised in increments of $1{ }^{\circ} \mathrm{C}$. Once the water bath temperature reached the desired level, the sample was allowed to fully equilibrate to that temperature for 
$2 \mathrm{~min}$, immediately prior to taking the measurement, each sample was gently agitated. The extinction at $260 \mathrm{~nm}$ of each sample was recorded. The preparation of DOPC liposome aggregates and the measurement of their melting curves were conducted according to a recent paper. ${ }^{54}$

The melting curves of free DNA were collected with a sample volume of $25 \mu \mathrm{L}$ containing 500 $\mathrm{nM}$ of each linker DNA, $600 \mathrm{nM}$ of the thiol-modified DNA (3'SH-DNA1 and 5'SH-DNA1, see Table 1 for sequences) and $5 \mu \mathrm{M}$ SYBR Green I in buffer C. The samples were loaded into a 96-well PCR plate and sealed with a plastic cover to avoid evaporation. The samples were analyzed using a Bio-Rad CFX96 real time PCR thermocycler with a heated lid $\left(105^{\circ} \mathrm{C}\right)$. The emission in the SYBR Green channel was monitored from 10 to $80{ }^{\circ} \mathrm{C}$ with $1{ }^{\circ} \mathrm{C}$ increment and $20 \mathrm{sec}$ holding time. The $T_{m}$ values were obtained from the first derivative of the melting curves. All the samples were run in triplicates.

\section{Results and Discussion}

System Design. To systematically study the effect of unpaired nucleotides, two sets of thiol-modified DNAs (Figure 1A, colored in green and orange, the thiol groups not shown) were used to functionalize AuNPs. Each DNA contained a 12-mer sequence for hybridization purposes. Two of the DNAs contained a nine-adenine spacer $\left(\mathrm{A}_{9}\right)$ between the thiol group and the hybridization sequence and the other two contained no such spacer $\left(\mathrm{A}_{0}\right)$. The AuNPs were assembled using a linker DNA. For the 24mer linker DNA, every nucleotide was base paired. Gaps or overhangs were present in longer linker DNAs. Upon assembly, the color of AuNPs changed from red to blue, allowing convenient monitoring of the assembly process. By heating the assembled AuNPs above its melting temperature $\left(T_{m}\right)$, the system disassembled giving dispersed red AuNPs. To study the effect of gaps in the linker DNA, varying number of insertions were introduced (Figure 1B). The effect of overhang DNA was studied by the addition of 5, 10, and 18 nucleotides on each end of the linker DNA (Figure 1C). Finally, the melting of free DNAs in the absence of AuNPs were also studied (Figure 1D, E). 


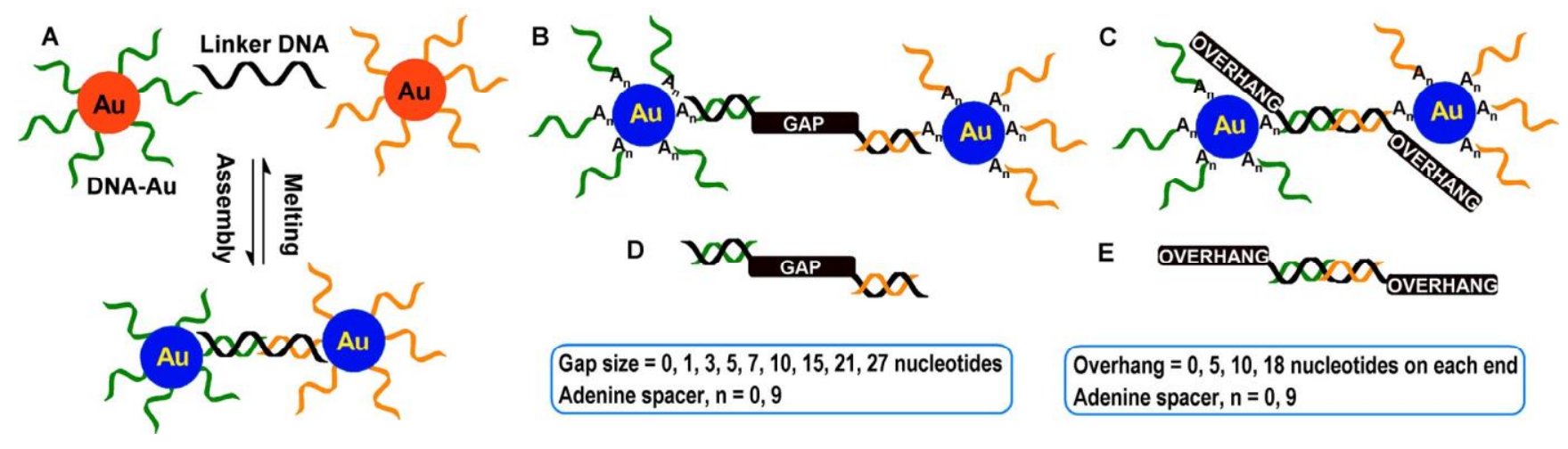

Figure 1. (A) Schematic representation of DNA directed assembly and melting of DNA-functionalized AuNPs. The AuNP arrangement in presence of nucleotide gaps (B) and overhangs (C). For clarity of the figures, only two AuNPs are shown. The actual aggregates are composed of hundreds to thousands of AuNPs. In some of AuNPs assemblies, a 9-adenine spacer $\left(\mathrm{A}_{9}\right)$ is also present. The melting of the free DNAs in the absence of AuNPs was also measured as a function of the gap size (D) and overhang length (E).

Assembly Kinetics as a Function of Gap Size. Dispersed $13 \mathrm{~nm}$ AuNPs have a characteristic extinction peak at $520 \mathrm{~nm}$ (Figure 2A, solid curve). Upon assembly by linker DNA, the $520 \mathrm{~nm}$ peak decreases and shifts to longer wavelength (dashed curve). We chose to use the extinction ratio of 650 over $520 \mathrm{~nm}$ to quantify the aggregation of AuNPs. For dispersed AuNPs, the ratio is lower than 0.15. This ratio starts to increase as the aggregation process proceeds. If this extinction ratio is plotted as a function of time, the kinetics of assembly can be obtained. For example, if the linker was the perfect 24-mer DNA, a significant color change was observed within 10 min (Figure 2B, open squares). In the absence of the linker, there was no color change (open dots). If a 27 nucleotide gap was present in the linker DNA, the assembly kinetics were significantly reduced (triangles). 
To further understand the effect of gap size, the extinction ratios at 10 min after reacting AuNPs with linker DNAs containing varying gap sizes were measured (Figure 2C, solid dots). This plot shows that the larger the gap size, the slower the hybridization kinetics, and an exponential decay curve is obtained. It needs to be pointed out that after a sufficiently long time (e.g. after one day), all of the samples were aggregated (Figure 2C, open squares). With a longer insertion in the linker DNA, the final extinction ratio was also lower, suggesting that the inter-particle distance was longer. ${ }^{25}$ The presence of a nineadenine spacer did not change the kinetic trend and an exponential decay in the assembly kinetics was still observed (Figure 2D). Using a standard protocol for measuring the DNA density on AuNPs, ${ }^{55}$ we estimated that each AuNP was functionalized by $92 \pm 9$ DNA (DNA used: 5'FAMATGCGGAGGAAGGTTTT-SH-3') and thus the concentration of DNA on AuNP was $\sim 460 \mathrm{nM}$. Therefore, we chose to use $200 \mathrm{nM}$ linker DNA to ensure that the linkers were sufficient but not too high to inhibit the assembly. ${ }^{56}$

The effect of nucleotide gaps on the assembly kinetics can be understood using a simple collision model. The longer the linker DNA, the higher the chance to form secondary structures within the molecules, and the smaller the chance for the AuNPs to encounter the hybridization sequence. Therefore, a longer time is needed for the AuNPs to be assembled. ${ }^{57}$ Unlike in the simple molecular binding assays, by monitoring the surface plasmon change of AuNPs, it is difficult to quantitatively correlate the color change with the DNA hybridization rate. Quantitative understandings may be achieved by computer modeling studies. These results suggest that while it is possible to assemble AuNPs with linker DNAs containing long stretches of insertions, a longer time is needed for aggregation to take place. 

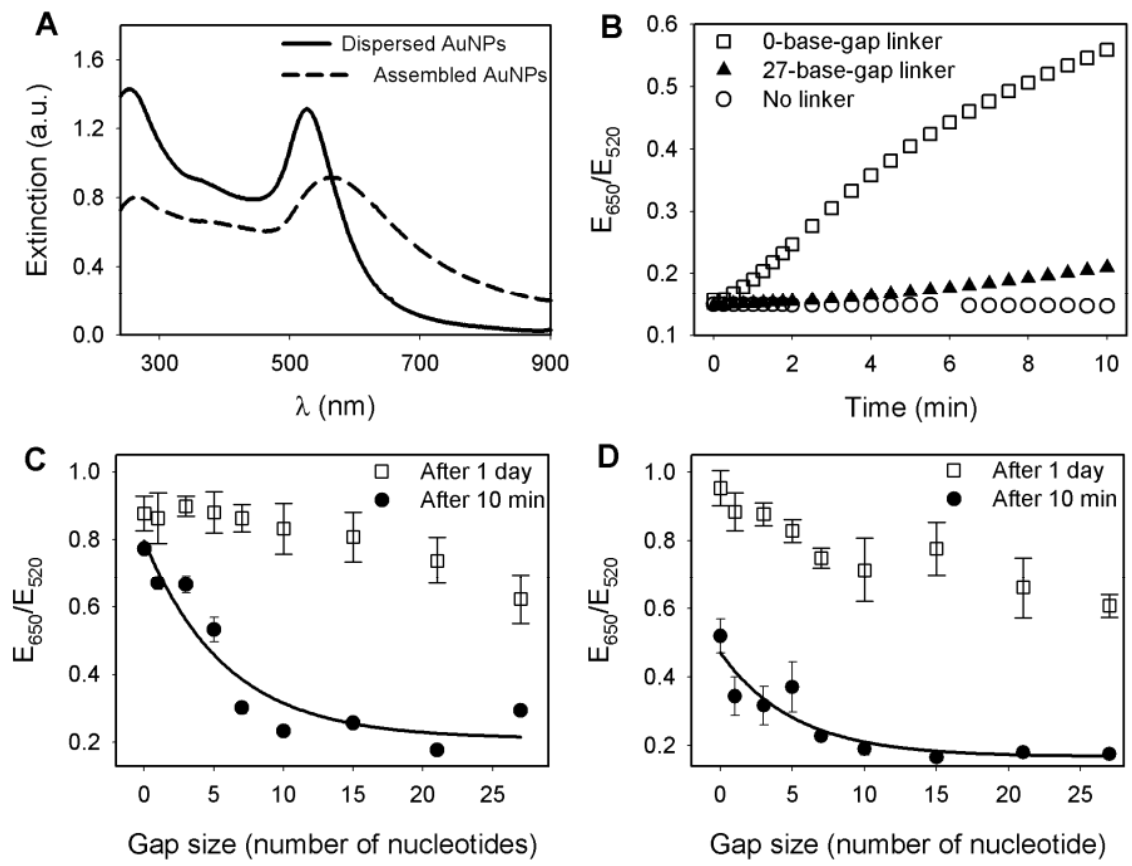

Figure 2. (A) UV-vis extinction spectra of dispersed and assembled $13 \mathrm{~nm}$ AuNPs. (B) Kinetics of AuNP assembly (with A9 spacer) monitored by the extinction ratio of 650 over $520 \mathrm{~nm}$. (C, D) The extinction ratio after 10 min or 1 day assembly in the presence of linker DNAs containing varying gap sizes. The thiol DNA contained either no adenine spacer (C) or a nine-adenine spacer (D).

Melting as a Function of Gap Size. One of the most important properties of DNA-assembled nanostructures is a sharp melting transition, which has been attributed to the cooperative melting of the multivalent DNA linkages. ${ }^{16}$ Because of this sharp transition, it is possible to detect single base mismatches using $T_{m}$ measurement. ${ }^{14,52}$ Previously, it was reported that a single nucleotide insertion decreased the $T_{m}$ by $\sim 3{ }^{\circ} \mathrm{C} .{ }^{52}$ There was however no report on the $T_{m}$ change as a function of gap size. Understandings related to this can help us explore the reason for the decrease in $T_{m}$ and better design smart nanomaterials.

We prepared AuNP aggregates assembled by the various linkers and measured their extinction at $260 \mathrm{~nm}$ as a function of temperature. As can be observed from Figure 2A, there was a large increase in 
the $260 \mathrm{~nm}$ extinction upon melting, allowing convenient monitoring of the melting process. In the first set of experiment, the thiol DNA on AuNPs did not contain any adenine spacer. Sharp melting transitions were observed for all of the samples (Figure 3A). The sample with the 24-mer linker (gap size $=0)$ had the highest $T_{m}$ of $39^{\circ} \mathrm{C}$ (Figure 3B). For samples with gap sizes between 1 and 7 nucleotides, the $T_{m}$ 's dropped to $\sim 38{ }^{\circ} \mathrm{C}$. Further increase of the gap size to between 10 and 21 , the $T_{m}$ 's were around $36{ }^{\circ} \mathrm{C}$. Finally, a $T_{m}$ of $31{ }^{\circ} \mathrm{C}$ was observed for the sample containing a gap size of 27 . Therefore, there is indeed a gap size-dependent decrease of $T_{m}$, although the dependence was quite weak.

If a 9-adenine spacer was introduced in the thiol DNAs, the decrease in $T_{m}$ was independent of the gap size and a $2-3{ }^{\circ} \mathrm{C}$ drop in $T_{m}$ was observed for all the samples (Figure $3 \mathrm{C}, \mathrm{D}$ ). The presence of the 9-adenine spacer also shifted the overall $T_{m}$ to higher values due to the relief of steric effects among AuNPs. ${ }^{16}$ Therefore, $T_{m}$ is a weak function of the gap size, especially with the presence of the 9adenine spacer. With the 24-mer linker, the two DNAs on the AuNPs can form a nicked duplex structure. As a result, DNA base stacking interactions can still take place to contribute to the stability of the system. With the first gap introduced, this stacking interaction was lost, ${ }^{58,59}$ which might explain the initial decrease in $T_{m}$. After that, base stacking energy should have no contribution to $T_{m}$ with further increasing the gap size. On the other hand, the presence of a gap increased the distance between AuNPs, which can be deduced from the extinction ratio of AuNPs after 1 day aggregation shown in Figure 2C-D. Unlike the 9-adenine spacer introduced on AuNPs, such increase of distance in the middle, however, had much less effect on the $T_{m}$ values. Interestingly, in a previous report where the effect of double-stranded gaps was studied, no decrease in $T_{m}$ was observed, which can be explained by that all the base stacking interactions were maintained by having the double-stranded gaps. ${ }^{25}$

To further understand the effect of AuNPs, melting curves of free DNAs were also measured using SYBR Green I as the signaling dye in a real-time PCR thermocycler. All the DNA linkages were the same except no AuNPs were involved (Figure 1D). Melting of the DNA resulted in release of the dye 
and a decrease in fluorescence. Since the melting of free DNA occurred over a much broader temperature range (see Supporting Information for the original melting curves), the first derivatives of the melting curves are plotted in Figure 3E and the $T_{m}$ values are shown in Figure 3F. All the samples showed a melting transition at $\sim 59^{\circ} \mathrm{C}$. Therefore $T_{m}$ did not change as a function of DNA length. In particular, there was no difference in the samples containing no gap or 1 nucleotide gap. This suggests that the presence of the nick already resulted in the lost of base stacking in the free DNAs ${ }^{58}$ The loss of stacking at the nick site is very likely to occur at high temperatures (e.g. close to the $T_{m}$ ). In the assembled AuNPs, the positions of the DNAs are largely fixed and the freedom was low. Therefore, it is likely that the DNAs can stay in the stacked form for a much longer time in comparison to the free DNAs. The samples with 3 and 10-nucleotide insertions also showed an additional melting transition at $\sim 48^{\circ} \mathrm{C}$. This might be due to the dissociation of SYBR Green I from the single-stranded region and this transition is also shown in Figure $3 \mathrm{~F}$ (gray dots). The $T_{m}$ values obtained in this experiment are higher than those in the AuNP case because SYBR Green I is known to increase DNA $T_{m} \cdot{ }^{60}$ To confirm our conclusion, we also did an independent experiment where the hyperchromic effect of DNA melting at $260 \mathrm{~nm}$ was measured (see Supporting Information) and all tested samples showed the same meting transitions, regardless of the gap size. 

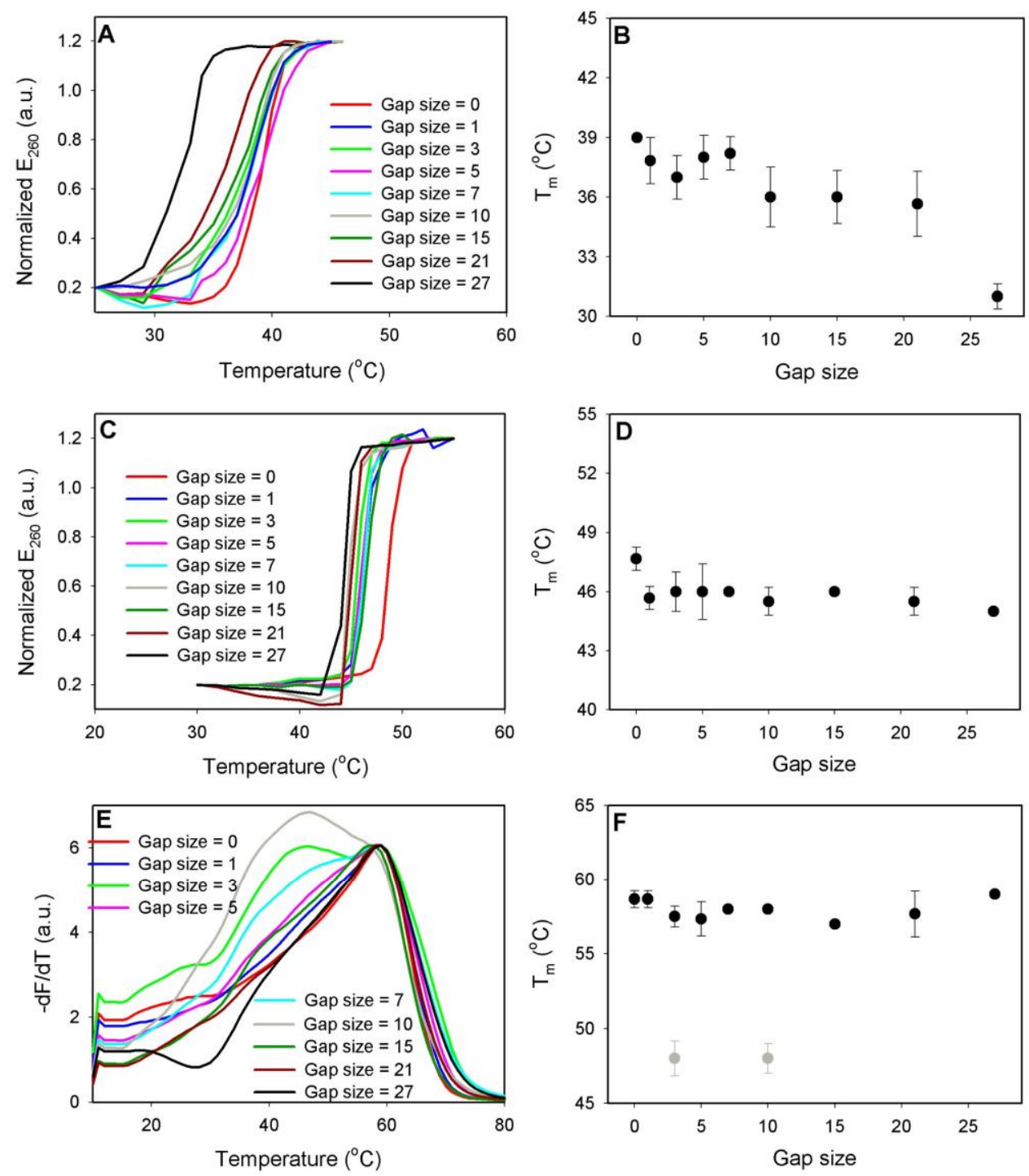

Figure 3. Melting curves (A, C) and melting temperatures (B, D) of AuNP assemblies linked with DNAs containing different gap sizes. The thiol DNA on AuNPs contained either no adenine spacer (A, B) or a nine-adenine spacer $(C, D)$. At least three independent samples were prepared and measured to obtain the standard deviation (error bar). For comparison, the melting curves (first derivative) of the free DNAs in the absence of AuNPs were also measured (E). The $T_{m}$ values in (E) were plotted as a function of gap size (F). Two of the samples showed two melting transitions and both $T_{m}$ 's were shown. The lower transitions were shown in gray dots. 
Effect of Nucleotide Overhangs. Next, we tested the effect of introducing overhangs to the linker DNA as shown in Figure 1C (Linker and Linker-O10, -O20, -O36 in Table 1). The assembly kinetics also decreased with increasing overhang sizes for samples without (Figure 4A) or with (Figure 4C) the 9adenine spacer. For the melting study, a significant drop in $T_{m}$ was observed with increasing of overhang size (Figure 4B, D). ${ }^{39}$ For example, with a 20 -mer overhang (10 on each end), the $T_{m}$ drop was greater than $10{ }^{\circ} \mathrm{C}$. Unlike in the case of the gap size, the $T_{m}$ is a strong function of the overhang size. In the case of the overhang, there is no loss in the base stacking energy, the $T_{m}$ drop can only be attributed to steric effects. For example, the distance between AuNPs is defined by the 24-mer linker DNA and the overhangs on the linker DNA is likely to interact with the thiol-labeled DNA on AuNPs to create electrostatic repulsion. These experiments also suggest that caution needs to be taken when designing such AuNP-based sensors for detecting biological nucleic acids, which may contain a very long overhang sequence. In that case, the drop in $T_{m}$ due to such overhangs may strongly influence the behavior of the system.

To ensure that the observed $T_{m}$ change was indeed due to steric effects, we further replaced the AuNPs in Figure 1C by DOPC liposomes (with the nine-adenine spacer) linked by the same DNAs. The melting of DNA-linked liposomes was recently reported and the extinction at $260 \mathrm{~nm}$ decreased instead of increasing upon melting due to reduced light scattering and reflection. ${ }^{54}$ Similar overhang sizedependent melting curves were obtained (Figure 4E). The surface property of AuNPs and DOPC liposomes are very different. For example, DNA does not bind to DOPC strongly in the absence of divalent metal ions ${ }^{61}$ but can still bind to AuNPs. ${ }^{62}$ The fact that a similar overhang-dependent $T_{m}$ drop was also observed for the liposome suggests the generality of the overhang effect. As a further control experiment, we also measured the melting curves of the free DNAs (Figure 1E). We found that all the DNAs had the same $T_{m}$ (Figure $\left.4 \mathrm{~F}\right)$. Therefore, it was the DNA-functionalized AuNPs that created the steric effect. 

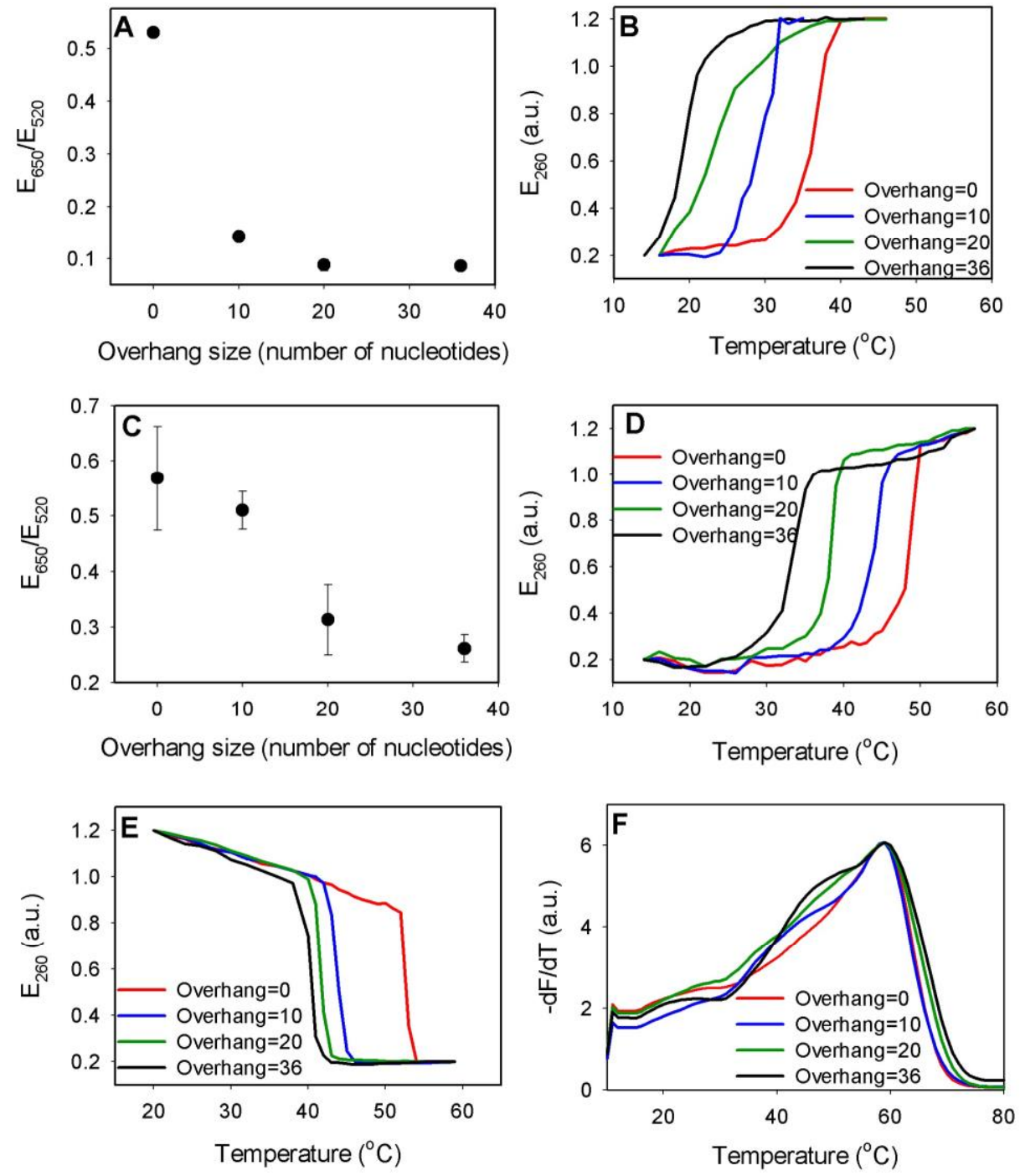

Figure 4. (A, C) The extinction ratio after 10 min assembly in the presence of linker DNA with varying overhang sizes. The thiol DNA contained either no adenine spacer (A) or a nine-adenine spacer (C). (B, D) Melting curves of AuNP assemblies linked by DNA containing different overhang sizes. The thiol DNA contained either no adenine spacer (B) or a nine-adenine spacer (D). The overhangs on both ends were included. (E) Melting curves of DNA linked DOPC liposomes. (F) Melting curves (first derivative) of the free DNAs. All the DNAs melted at $59^{\circ} \mathrm{C}$. 


\section{Conclusions}

In summary, we have performed systematic studies on the assembly of DNA-functionalized AuNPs using linker DNAs containing varying sizes of gaps and overhangs. Overall, the kinetics of assembly decreased with increasing gap or overhang sizes, which can be attributed to the decreased possibility of finding the hybridization sequence within longer linker DNA. On the other hand, the presence of gaps resulted in a loss of DNA base stacking energy. Therefore, this had little effect on the $T_{m}$ with increasing gap size after the introduction of the first gap. Interestingly, the presence of gap had no effect on the melting of the free DNAs, suggesting that by fixing the DNAs in the nanoparticle assembly, base stacking at the nick site was more effective. In the case of the overhangs, a large drop in $T_{m}$ was observed, which can be attributed to steric interactions between the overhang and attached DNA to AuNPs.

\section{Acknowledgment}

Funding for this work is from the University of Waterloo and the Discovery Grant and Undergraduate Research Fellowships from the Natural Sciences and Engineering Research Council of Canada (NSERC).

\section{Reference:}

(1) Storhoff, J. J.; Mirkin, C. A. Chem. Rev. 1999, 99, 1849.

(2) Seeman, N. C. Nature 2003, 421, 427.

(3) Katz, E.; Willner, I. Angew. Chem., Int. Ed. 2004, 43, 6042.

(4) Feldkamp, U.; Niemeyer, C. M. Angew. Chem., Int. Ed. 2006, 45, 1856.

(5) Lu, Y.; Liu, J. Acc. Chem. Res. 2007, 40, 315.

(6) Zhao, W.; Brook, M. A.; Li, Y. Chembiochem 2008, 9, 2363.

(7) Lin, C.; Liu, Y.; Yan, H. Biochemistry 2009, 48, 1663.

(8) Geerts, N.; Eiser, E. Soft Matter 2010, 6, 4647. 
(9) Mirkin, C. A.; Letsinger, R. L.; Mucic, R. C.; Storhoff, J. J. Nature 1996, 382, 607.

(10) Alivisatos, A. P.; Johnsson, K. P.; Peng, X.; Wilson, T. E.; Loweth, C. J.; Bruchez, M. P., Jr; Schultz, P. G. Nature 1996, 382, 609.

(11) Park, S. Y.; Lytton-Jean, A. K. R.; Lee, B.; Weigand, S.; Schatz, G. C.; Mirkin, C. A. Nature 2008, $451,553$.

(12) Nykypanchuk, D.; Maye, M. M.; van der Lelie, D.; Gang, O. Nature 2008, 451, 549.

(13) Maye, M. M.; Kumara, M. T.; Nykypanchuk, D.; Sherman, W. B.; Gang, O. Nat. Nanotechnol. 2010, 5, 116.

(14) Elghanian, R.; Storhoff, J. J.; Mucic, R. C.; Letsinger, R. L.; Mirkin, C. A. Science 1997, 277, 1078.

(15) Mucic, R. C.; Storhoff, J. J.; Mirkin, C. A.; Letsinger, R. L. J. Am. Chem. Soc. 1998, 120, 12674.

(16) Jin, R.; Wu, G.; Li, Z.; Mirkin, C. A.; Schatz, G. C. J. Am. Chem. Soc. 2003, 125, 1643.

(17) Liu, J.; Lu, Y. Angew. Chem., Int. Ed. 2006, 45, 90. (18) Liu, J.; Lu, Y. J. Am. Chem. Soc. 2005, 127, 12677.

(19) Pavlov, V.; Xiao, Y.; Shlyahovsky, B.; Willner, I. J. Am. Chem. Soc. 2004, 126, 11768.

(20) Rosi, N. L.; Mirkin, C. A. Chem. Rev. 2005, 105, 1547.

(21) Liu, J.; Cao, Z.; Lu, Y. Chem. Rev. 2009, 109, 1948.

(22) Lu, Y.; Liu, J. Curr. Opin. Biotechnol. 2006, 17, 580.

(23) Rosi, N. L.; Giljohann, D. A.; Thaxton, C. S.; Lytton-Jean, A. K. R.; Han, M. S.; Mirkin, C. A. Science 2006, 312, 1027.

(24) Giljohann, D. A.; Seferos, D. S.; Daniel, W. L.; Massich, M. D.; Patel, P. C.; Mirkin, C. A. Angew. Chem. Int. Ed. 2010, 49, 3280.

(25) Storhoff, J. J.; Lazarides, A. A.; Mucic, R. C.; Mirkin, C. A.; Letsinger, R. L.; Schatz, G. C. J. Am. Chem. Soc. 2000, 122, 4640. 
(26) Liu, J.; Lu, Y. J. Am. Chem. Soc. 2004, 126, 12298.

(27) Liu, J. W.; Lu, Y. J. Am. Chem. Soc. 2003, 125, 6642.

(28) Lee, J. H.; Wang, Z.; Liu, J.; Lu, Y. J. Am. Chem. Soc. 2008, 130, 14217.

(29) Xue, X. J.; Wang, F.; Liu, X. G. J. Am. Chem. Soc. 2008, 130, 3244.

(30) Lee, J.-S.; Han, M. S.; Mirkin, C. A. Angew. Chem., Int. Ed. 2007, 46, 4093.

(31) Liu, J. W.; Lu, Y. Angew. Chem. Int. Ed. 2006, 45, 90.

(32) Li, F.; Zhang, J.; Cao, X. N.; Wang, L. H.; Li, D.; Song, S. P.; Ye, B. C.; Fan, C. H. Analyst 2009, 134, 1355.

(33) Zhao, W. A.; Lam, J. C. F.; Chiuman, W.; Brook, M. A.; Li, Y. F. Small 2008, 4, 810.

(34) Medley, C. D.; Smith, J. E.; Tang, Z.; Wu, Y.; Bamrungsap, S.; Tan, W. H. Anal. Chem. 2008, 80,1067

(35) Perez, J. M.; O'Loughin, T.; Simeone, F. J.; Weissleder, R.; Josephson, L. J. Am. Chem. Soc. $2002,124,2856$.

(36) Yigit, M. V.; Mazumdar, D.; Kim, H.-K.; Lee, J. H.; Odintsov, B.; Lu, Y. ChemBioChem 2007, 8,1675 .

(37) Mitchell, G. P.; Mirkin, C. A.; Letsinger, R. L. J. Am. Chem. Soc. 1999, 121, 8122.

(38) Sadasivan, S.; Dujardin, E.; Li, M.; Johnson, C. J.; Mann, S. Small 2005, 1, 103.

(39) Liu, J.; Lu, Y. J. Am. Chem. Soc. 2007, 129, 8634.

(40) Harris, N. C.; Kiang, C. H. J. Phys. Chem. B 2006, 110, 16393.

(41) Harris, N. C.; Kiang, C. H. Phys. Rev. Lett. 2005, 95.

(42) Jones, M. R.; Macfarlane, R. J.; Lee, B.; Zhang, J.; Young, K. L.; Senesi, A. J.; Mirkin, C. A. Nat. Mater. 2010, 9, 913.

(43) Lee, O. S.; Prytkova, T. R.; Schatz, G. C. J. Phys. Chem. Lett. 2010, 1, 1781.

(44) Ellington, A. D.; Szostak, J. W. Nature 1990, 346, 818. 
(45) Tuerk, C.; Gold, L. Science 1990, 249, 505.

(46) Robertson, D. L.; Joyce, G. F. Nature 1990, 344, 467.

(47) Macfarlane, R. J.; Lee, B.; Hill, H. D.; Senesi, A. J.; Seifert, S.; Mirkin, C. A. Proc. Natl. Acad. Sci. U.S.A. 2009, 106, 10493.

(48) Hill, H. D.; Macfarlane, R. J.; Senesi, A. J.; Lee, B.; Park, S. Y.; Mirkin, C. A. Nano Lett. 2008, $8,2341$.

(49) Maye, M. M.; Nykypanchuk, D.; van der Lelie, D.; Gang, O. J. Am. Chem. Soc. 2006, 128, 14020.

(50) Prigodich, A. E.; Lee, O.-S.; Daniel, W. L.; Seferos, D. S.; Schatz, G. C.; Mirkin, C. A. J. Am. Chem. Soc. 2010, 132, 10638.

(51) Parpart, S. T.; Tison, C. K.; Milam, V. T. Soft Matter 2010, 6, 3832.

(52) Storhoff, J. J.; Elghanian, R.; Mucic, R. C.; Mirkin, C. A.; Letsinger, R. L. J. Am. Chem. Soc. 1998, $120,1959$.

(53) Liu, J.; Lu, Y. Nat. Protoc. 2006, 1, 246.

(54) Dave, N.; Liu, J. Acs Nano 2011, 5, 1304.

(55) Demers, L. M.; Mirkin, C. A.; Mucic, R. C.; Reynolds, R. A., III; Letsinger, R. L.; Elghanian, R.; Viswanadham, G. Anal. Chem. 2000, 72, 5535.

(56) Huang, C.-C.; Huang, Y.-F.; Cao, Z.; Tan, W.; Chang, H.-T. Anal. Chem. 2005, 77, 5735.

(57) Stillman, B. A.; Tonkinson, J. L. Anal. Biochem. 2001, 295, 149.

(58) Protozanova, E.; Yakovchuk, P.; Frank-Kamenetskii, M. D. J. Mol. Biol. 2004, 342, 775.

(59) Yakovchuk, P.; Protozanova, E.; Frank-Kamenetskii, M. D. Nucleic Acids Res. 2006, 34, 564.

(60) Gudnason, H.; Dufva, M.; Bang, D. D.; Wolff, A. Nucleic Acids Res. 2007, 35, e127.

(61) Fedorov, B.; D'Yachkov, P.; Zhdanov, R. Russ. Chem. Bull. 1999, 48, 2046.

(62) Li, H.; Rothberg, L. Proc. Natl. Acad. Sci. U.S.A. 2004, 101, 14036. 